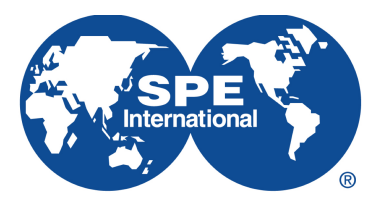

Society of Petroleum Engineers

\title{
SPE-187047-MS
}

\section{Detecting Poor Cement Bonding and Zonal Isolation Problems using Magnetic Cement Slurries}

\author{
Sriramya D. Nair, The University of Texas at Austin; Tadeusz W. Patzek, King Abdullah University of Science and \\ Technology; Eric van Oort, The University of Texas at Austin
}

Copyright 2017, Society of Petroleum Engineers

This paper was prepared for presentation at the Annual Technical Conference and Exhibition held in San Antonio, Texas, U.S.A., 9-11 October 2017

This paper was selected for presentation by an SPE program committee following review of information contained in an abstract submitted by the author(s). Contents of the paper have not been reviewed by the Society of Petroleum Engineers and are subject to correction by the author(s). The material does not necessarily reflect any position of the Society of Petroleum Engineers, its officers, or members. Electronic reproduction, distribution, or storage of any part of this paper without the written consent of the Society of Petroleum Engineers is prohibited. Permission to reproduce in print is restricted to an abstract of not more than 300 words; illustrations may not be copied. The abstract must contain conspicuous acknowledgment of SPE copyright.

\section{Abstract}

There has been growing interest in the use of magnetorheological fluids to improve displacement efficiency of fluids (drilling fluids, spacer fluids, cement slurries) in the eccentric casing annuli. When magnetic particles are mixed with the cement slurry for improved displacement, they provide an excellent opportunity for sensing the presence and quality of cement in the annulus. This work focuses on using sophisticated 3D computational electromagnetics to simulate the use of a magnetic cement slurry for well cement monitoring. The main goal is to develop a new tool, which is capable of locating magnetic cement slurry that is placed behind a stainless steel casing. An electromagnetic coil was used to generate a magnetic field inside the borehole. It was found that when a current was passed through the electric coils, magnetic field lines passed through the stainless steel casing, the cement annulus and the rock formation. Three sensors were placed inside the cased borehole and the magnetic field strength variations were observed at these locations. Various factors that have a significant influence on zonal isolation were considered. These include, effect of debonding between casing and cement annulus, effect of changing annuli thickness, influence of a fracture in the rock formation, effect of changing magnetic permeability of cement and finally influence of annuli eccentricity. Based on the results shown in the paper along with the next generation of supersensitive magnetic sensors that are being developed, the magnetic approach appears to be a viable alternative for evaluating the quality of the cement annulus to ensure good zonal isolation.

\section{Introduction}

The main goal of a cement job is to provide a complete and durable zonal isolation from when the cement is placed, up until the well is abandoned. Zonal isolation is extremely important in the oil and gas industry since it prevents fluids (such as water or gas) in one zone from mixing with oil in another zone. The ability of the cement sheath to provide zonal isolation depends on the cement/casing interface, the bulk cement and the cement/formation interface (Nelson and Guillot 2006). The bulk cement layer could be affected, for example, if there is gas or liquid migration into the cement during placing or if there are regions without any cement.

Cementing problems were associated with 18 of 39 blowouts between 1992 and 2006 (Izon et al. 2004), and based on a survey conducted in 1997, it was found that on average $5 \%$ of total well costs were spent on cementing and that $15 \%$ of the cementing jobs ended up in failure costing the industry $\$ 470$ million/year in repairs (Sabins 2002). Failure of a cementing job could lead to oil spills (e.g., BP oil spill, 2010) that result in both 
immediate and long-term environmental damage and destruction of ecosystems. Furthermore, oil spills not only affect human health due to indirect and direct inhalation and ingestion of contaminated products, but they also cause substantial monetary burdens to society (West 2011). Having better control over displacement of cement slurry during cementing could help avoid zonal isolation problems that arise from poor cementing. To this end there has been growing interest in the use of magnetorheological fluids to improve displacement efficiency of fluids (drilling fluids, spacer fluids, cement slurries) in the eccentric casing annuli (Nair et al. 2015; Ermila et al. 2012, 2013). This new technique is based on the principles of magneto-rheology, where an external magnetic field is applied to a fluid carrying magnetic particles (also known as a magnetorheological fluid). In the presence of the magnetic field, the rheological properties of such a modified slurry change instantaneously to cause a stiffening behavior characterized by yield point values that are increased by several orders of magnitude. By varying the intensity and the direction of the magnetic field as well as the dosage of magnetic particles, the flow properties of the slurry can be altered and the flow can be beneficially directed as desired.

When magnetic particles are mixed with the cement slurry for improved displacement, they provide an excellent opportunity for sensing the presence and quality of cement in the annulus using magnetic methods. There are many magnetic susceptibility logging tools currently being used in the industry for various applications such as mineral exploration, lithology studies, determination of magnetic mineral content, ore exploration (examples include: Slimline by Weatherford; BSS-02B by Bartington instruments, QL40-HM by Mount Sopris Instruments). Most of the tools are used in open holes (no casing) in a wide temperature and pressure range, some tools are designed to operate in non-magnetic and non-conductive casing (polyvinylchloride). In the published literature there is no mention of the use of such magnetic tools for analyzing the quality of cement. This work focuses on using sophisticated computational 3D electromagnetics to simulate the use of a magnetic cement slurry for well cement monitoring. The objective is to develop a technique using magnetic sensors for verifying the quality of cement annulus in a borehole environment behind a stainless steel casing. Factors that have a significant influence on zonal isolation will be considered. These include effect of:

- debonding between casing and cement annulus

- changing annuli thickness

- formation fracture on the magnetic field distribution

- changing magnetic permeability of cement

- annuli eccentricity

The proposed technique extends the capabilities of existing cement monitoring techniques. The existing literature on magnetorheological cements is focused towards improved displacement, whereas this work presents a significant additional advantage for using such cement slurries for advanced monitoring. When aided by the next generation of supersensitive magnetic sensors that are being developed at Brown University and KAUST, this approach may offer significant advantages through state-of-the art in cement fault detection.

\section{Background}

\section{Casing}

Most casings are made of carbon steel such as grade 1008 which have high magnetic permeabilities of the order of 1000 because of which the magnetic field lines do not penetrate the casing. Thus for this project, a casing with a low magnetic permeability was chosen. Annealed austenitic stainless steels have higher chromium content and the addition of nickel alters the physical structure making them non-magnetic (for example, grades 304, 310, 316) (Lai et al. 2012). 100\% austenitic structures are non-magnetic (magnetic permeability = 1), but in practice small amount of ferrite and/or martensite can be present in the final structure resulting in permeabilities slightly above 1. Processes such as strain hardening, used for strengthening steel or welding can also make them slightly magnetic. For the present study, casing with grade SS-304 was chosen because it is the most commonly used type of stainless steel. 


\section{Magnetic Cement Slurry}

Portland cement (such as Class $\mathrm{H}$ cement) typically contains about $2-3 \%$ iron oxide. As shown in Fig. 1a, this small percentage of iron oxide causes cement to exhibit weak ferromagnetic behavior (S-shape curve). From the figure it can also be seen that the magnetic permeability $\left(\mu=1+\right.$ magnetic susceptibility $\left.\left(\chi_{m}\right)\right)$ of cement is very close to one. Fig. 1b, shows the behavior of carbonyl iron powder (CIP). Among various types of iron particles, CIP has a relatively high saturation magnetization $\left(1710 \mathrm{emu} / \mathrm{cm}^{3}=1710\right.$ Gauss $)$ and high susceptibility (7.9). It reaches within $10 \%$ of its saturation magnetization at an external applied field of 5000 Gauss $(0.5 \mathrm{~T})$. In Fig. 1 upon removal of an external magnetic field of $15000 \mathrm{G}$, the remanent magnetization of CIP was measured to be $15 \mathrm{emu} / \mathrm{cm}^{3}$, which could be within the experimental error. Once the magnetic field is removed, the particles reach their non-magnetic state within tens of milliseconds (Deshmukh 2007). Iron oxide reaches its saturation magnetization of $430 \mathrm{emu} / \mathrm{cm}^{3}$ at an external applied field of 300 Gauss. (Nair 2013).

When magnetic particles (say, CIP) are added to cement slurry, the magnetic properties of the slurry are based on the volume of magnetic particles. When $10 \%$ CIP particles were added to the cement slurry by weight of cement (or $4 \%$ by volume of cement), the saturation magnetization was $30 \mathrm{emu} / \mathrm{cm}^{3}$ and the magnetic permeability was 1.085 (Nair 2013). With further addition of magnetic particles, the magnetic permeability can be further increased, but the reported values are below 2.0 (Nair et al. 2015). So for this study, the relative magnetic permeability of cement slurry with magnetic particles is assumed to be 1.5 .
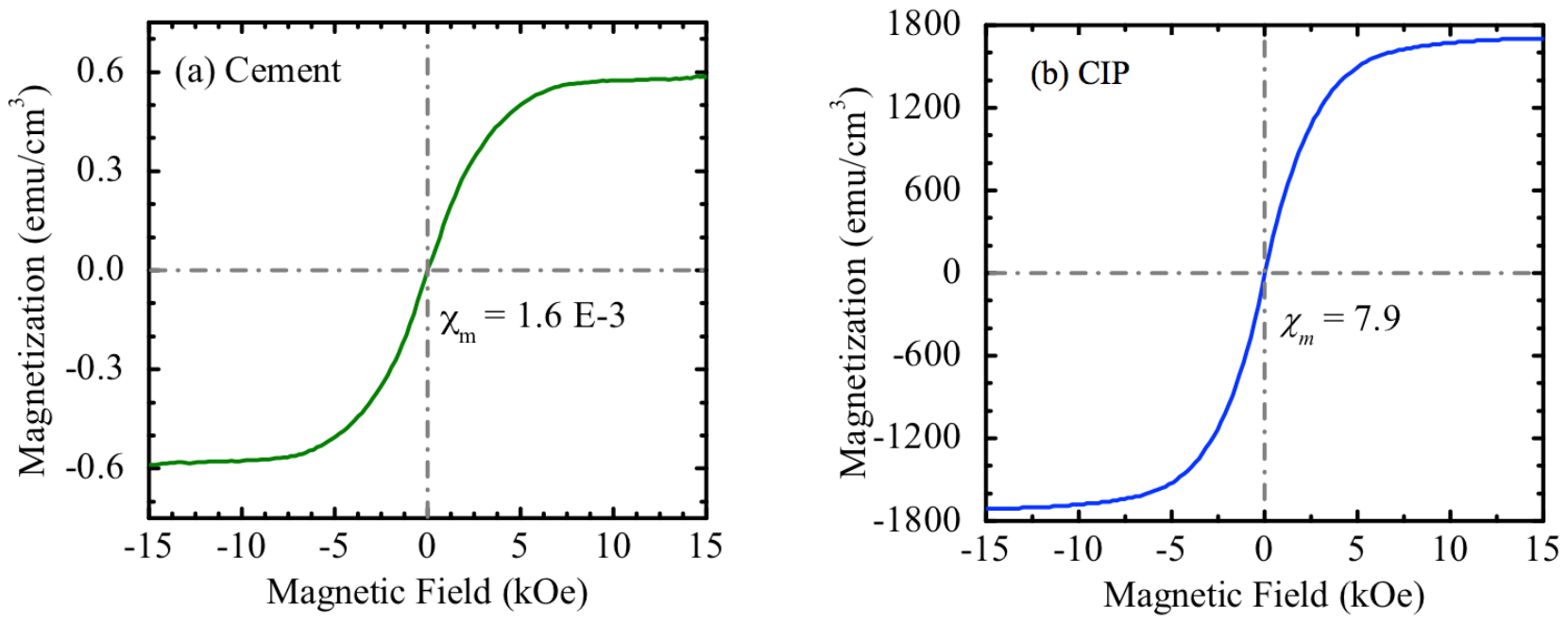

Fig. 1: Magnetization curves with values of magnetic susceptibility (a) Cement (b) CIP (Nair 2013).

\section{Simulations}

Simulations were run using the full educational version of CST Studio Suite. Along with the Electromagnetic Solver (EMS) the software also has the MPhysics tool for incorporating thermal and mechanical stresses. The electromagnetic properties of the materials used in the simulations are shown in Table 1. The magnetic permeability of the rock formation as well as the space inside the casing was assumed to be 1 . The magnetic cement slurry (MagCem) was designed as a linear magnetic material.

Table 1: Material Properties

\begin{tabular}{|l|c|r|r|r|r|r|}
\hline Property & Unit & Air & Steel-1008 & SS-304 & Cement & MagCem \\
\hline Electrical Permeability $(\varepsilon)$ & - & 1.00059 & 1 & 1 & 1 & 1 \\
Magnetic Permeability $(\mu)$ & - & 1 & 1000 & 1.05 & 1 & 1.5 \\
\hline
\end{tabular}


The borehole geometry considered was $21.6 \mathrm{~cm}$ (8.5") diameter bore hole which was $150 \mathrm{~cm}$ (60") deep with a $15.2 \mathrm{~cm} \mathrm{ID} \mathrm{x} 17.8 \mathrm{~cm}$ OD (6" ID x 7" OD) stainless steel casing (SS-304) as shown in Fig. 2. The thickness of the cement annulus is $1.91 \mathrm{~cm}(0.75 ")$. As shown in Fig. 2 three sensor locations were identified inside the cased hole and the magnetic field variation was monitored at these locations for various zonal isolation issues. The borehole depth considered is acceptable because as one goes farther away from the source, magnetic field strength decreases quickly. For example, in permanent magnets, the magnetic field decays at a rate of $1 /$ distance $^{3}$. In practice, as the tool is lowered down the borehole, a 3D image can be obtained to evaluate the quality of the cement annuli.

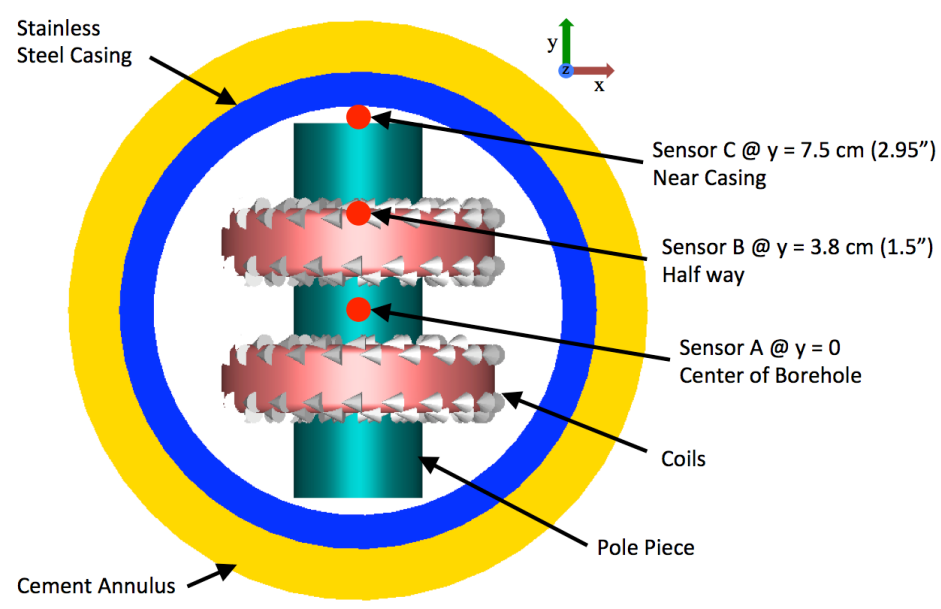

Fig. 2: Cross section of borehole at depth $50 \mathrm{~cm}$ with three possible locations for magnetic sensors.

\section{Coil Configurations for Application of Magnetic Field}

First, we evaluate the various sources of magnetic field. The main goal is to magnetize the magnetic particles in the cement annulus. Thus it is important to find a coil configuration that can produce the strongest magnetic field in the cement annulus. An obvious choice is a solenoid, which is a tightly wound helical coil. When an electric current is passed through the solenoid, uniform magnetic field is generated in the space within the coil. Because magnetic field lines have to form a loop, there is a detectable magnetic field outside the coil. The magnetic field along the axis of the coil can be calculated using the equation (Dennison 2015) :

$$
B=\frac{\mu_{o} i n}{2\left(r_{2}-r_{1}\right)}\left[x_{2} \ln \left(\frac{\sqrt{r_{2}^{2}+x_{2}^{2}}+r_{2}}{\sqrt{r_{1}^{2}+x_{2}^{2}}+r_{1}}\right)-x_{1} \ln \left(\frac{\sqrt{r_{2}^{2}+x_{1}^{2}}+r_{2}}{\sqrt{r_{1}^{2}+x_{1}^{2}}+r_{1}}\right)\right]
$$

where $=$

$B \quad=$ magnetic field, in $\mathrm{T}$, at any point on the axis of the coil

$\mu_{0} \quad=$ permeability constant

$i \quad=$ current in the wire, in amperes

$n \quad=$ total number of turns of wire in the coil

$r_{1}=$ inner radius of the coil, in meters

$r_{2}=$ outer radius of the coil, in meters

$l \quad=$ length of the coil, in meters

$x_{1}, x_{2}=$ distances from the ends of the solenoid to the measurement point, in meters 
To increase the magnetic field strength outside the coil, a pole piece made of iron (say, Steel-1008) can be used. In the current work, a coil with properties shown in Table 3 was wrapped helically around a cylindrical pole piece (14 cm long, $2.54 \mathrm{~cm}$ radius). However, the pole piece along with the presence of magnetic cement material in the vicinity of the coil complicates the equation. Thus, the 3D electromagnetic software is essential to gain a better understanding regarding magnetic field strength in a complicated environment.

Table 3: Parameters for schematic shown in Fig. 2

\begin{tabular}{|c|c|l|}
\hline Coil Parameter & Unit & Value \\
\hline $\mathrm{i}$ & $\mathrm{A}$ & $1 / 5 / 10$ \\
$\mathrm{n}$ & & 1000 \\
$\mathrm{r}_{1}, \mathrm{r}_{2}$ & $\mathrm{~cm}$ & $2.54,5.08$ \\
1 & $\mathrm{~cm}$ & 2.54 \\
\hline Coil location: & & $(\mathrm{x}, \mathrm{y}, \mathrm{z})$ \\
\hline Axis of coil 1 & $\mathrm{cm}$ & $(0,1.27$ to $3.81,50)$ \\
Axis of coil 2 & $\mathrm{cm}$ & $(0,-1.27$ to $-3.81,50)$ \\
\hline Pole Piece: & & \\
\hline Length & $\mathrm{cm}$ & 14 \\
Radius & $\mathrm{cm}$ & 2.54 \\
\hline
\end{tabular}

First, a coil with a cylindrical pole piece was aligned along the depth of the well, with two additional Steel-1008 pieces attached at the top and bottom to form an I-shaped steel core that spans the entire crosssection of the cased hole(see Fig. 3a). When an electric current was passed through this configuration, the magnetic field lines/contour generated are shown in Fig. 3b. To generate a more uniform magnetic field all across the cement annulus (Fig. 4b), the coil with pole piece were attached to two disks as shown in Fig. 4a. Various geometric proportions were considered for both I-shaped core and I-disk core.
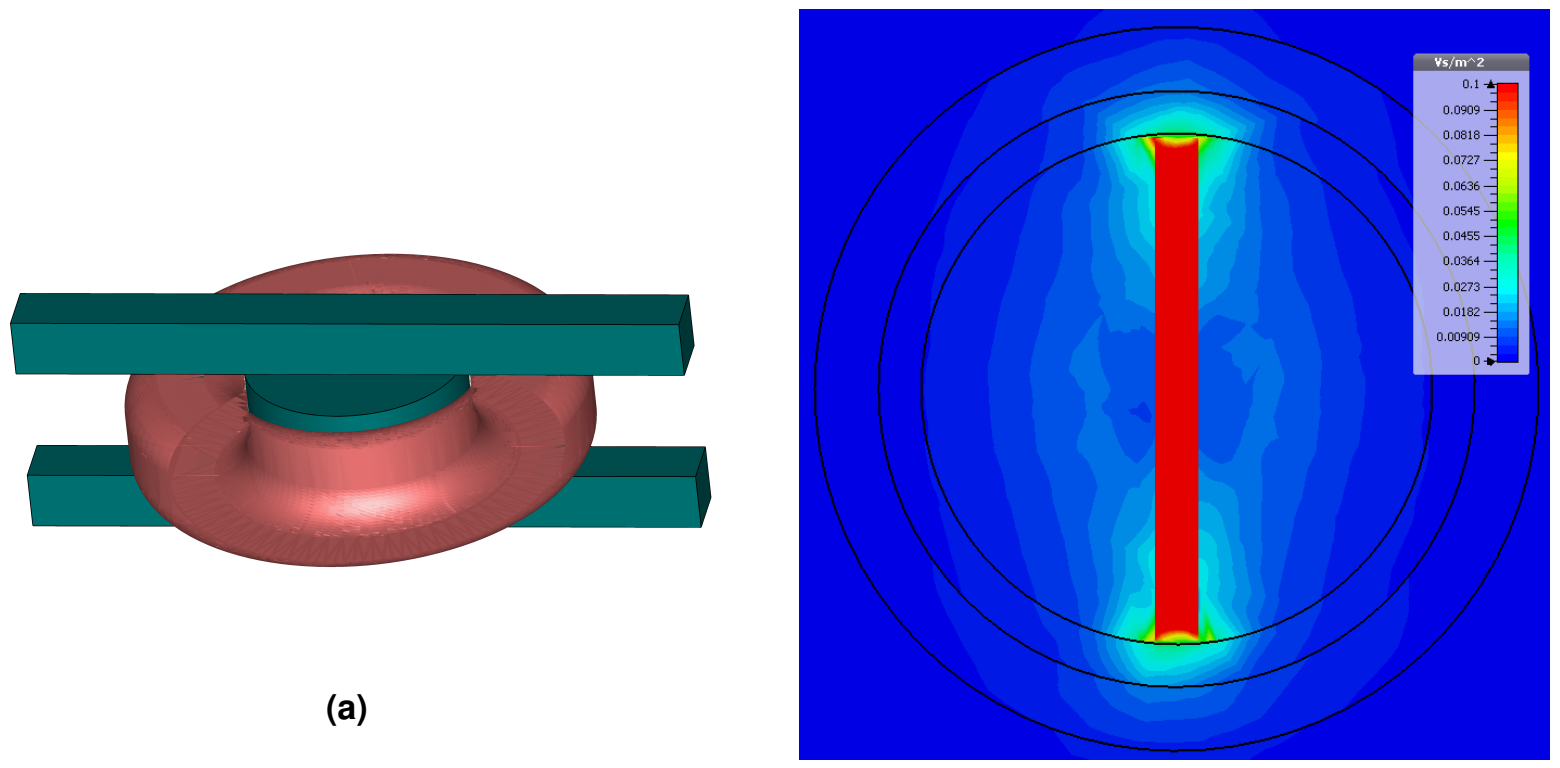

(b)

Fig. 3: (a) Schematic of l-shaped steel-1008 core with a coil in the center. (b) Magnetic field contours at a borehole cross section. Note: The color ramp at or above $0.1 \mathrm{~T}$ (or 1000 Gauss) is shown in red and a strength of zero is shown in blue. 


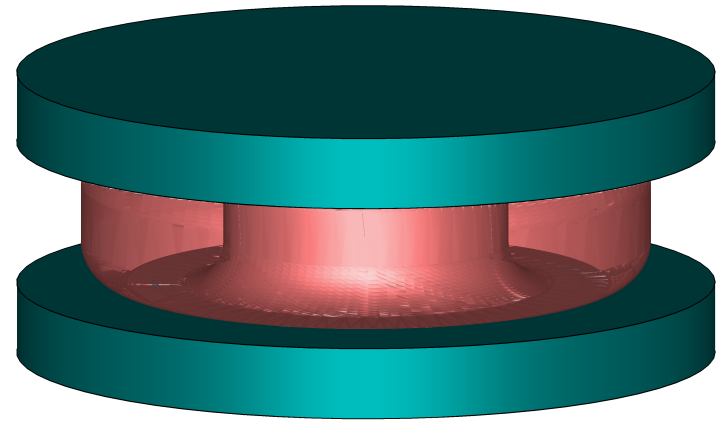

(a)

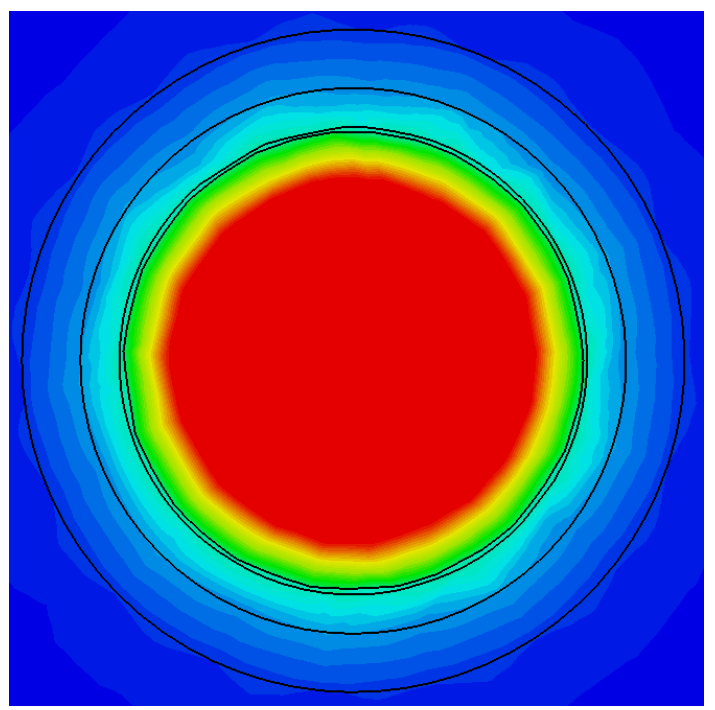

(b)

Fig. 4: (a) Discs at top and bottom to evenly distribute the magnetic field around the annulus. (b) Magnetic field contours at a borehole cross section. Note: The color ramp at or above $0.1 \mathrm{~T}$ (or 1000 Gauss) is shown in red and a strength of zero is shown in blue.

However, when the coils with pole piece was aligned in the radial direction of the borehole (as shown in Fig. 5a), significantly higher magnetic field strengths were obtained in the cement annulus (Fig. 6). Thus this configuration was used for the remainder of the simulations. In the field, to evaluate the entire cross section of the well, the pole piece can be rotated at a known speed. For the pole piece aligned in the radial direction of the borehole, the magnetic field strength in the annulus was affected by the magnitude of current that is passed through the coil. Higher the current, stronger the magnetic field strength (Fig. 6). When the magnetic field strength was calculated using Eq. 1, the magnetic field strength in the cement annulus was lower by approximately a factor of 300 . Thus the pole piece is useful for both directing the magnetic field as well as magnifying the strength.

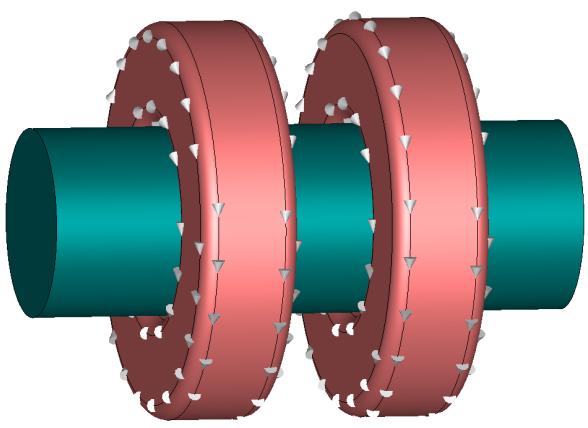

(a)

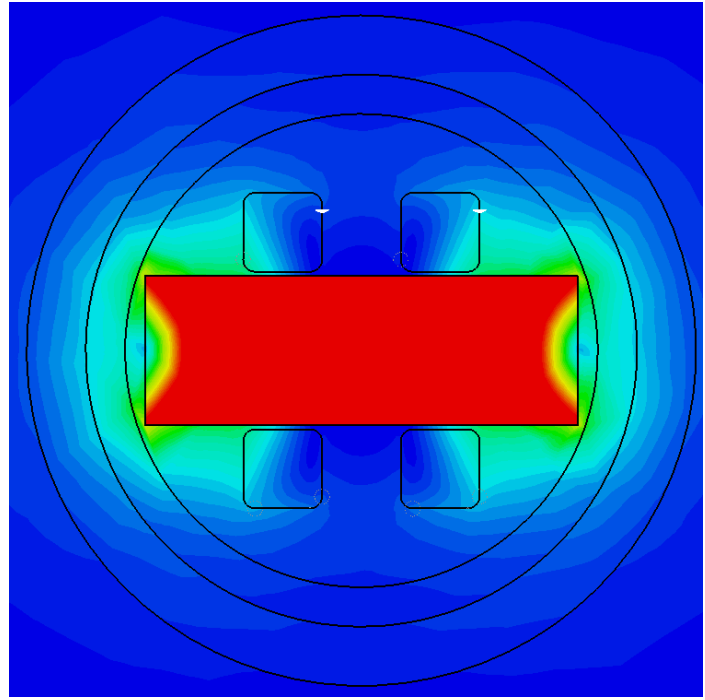

(b)

Fig. 5: Schematic of pole piece with coils. (b) Magnetic field contours at a borehole cross section. Note: The color ramp at or above $0.1 \mathrm{~T}$ (or 1000 Gauss) is shown in red and a strength of zero is shown in blue. 


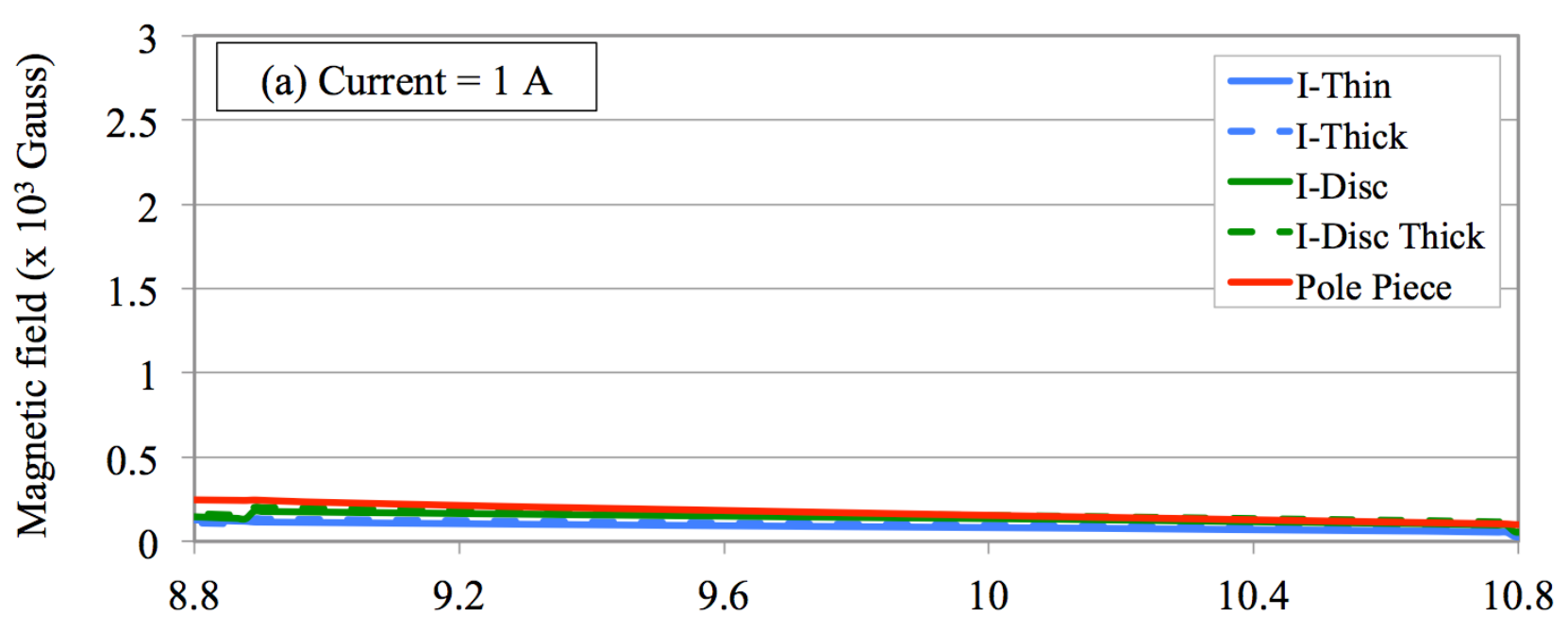

Radial distance along cement annulus at fixed depth (cm)

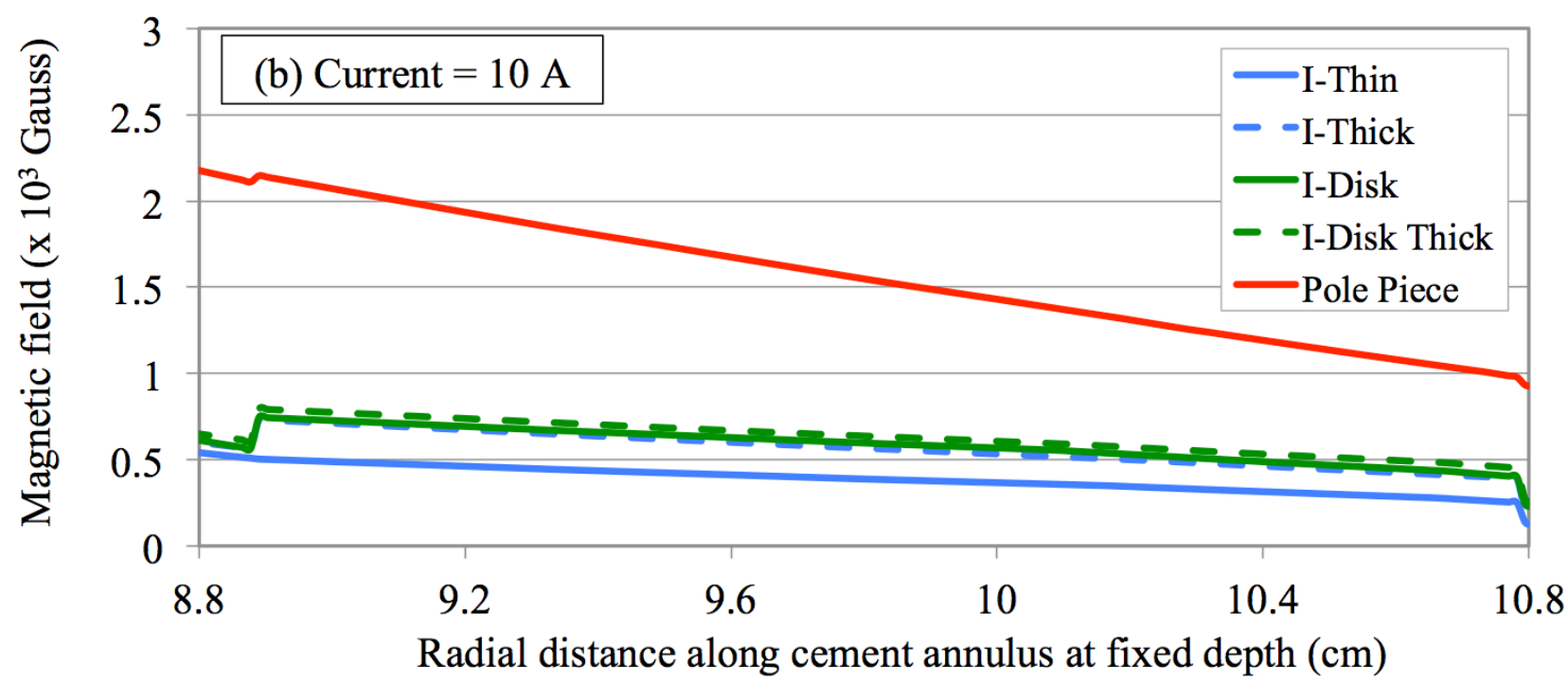

Fig. 6: Magnetic field variation for different configurations at (a) $1 \mathrm{~A}$ and (b) $10 \mathrm{~A}$ applied current.

\section{Capability of Detecting Zonal Isolation Problems Effect of Debonding between Casing and Cement Annulus}

After cement has set, over the life of the well there are many factors that lead to cracking/debonding between cement and casing Fig. 7. These factors include gradual pressure decrease as a well is produced, casing movement as subsidence occurs, cement shrinkage with time, temperature and pressure fluctuations and finally stimulation practices, such as hydraulic fracturing (Carpenter et al. 1992; Nelson and Guillot 2006; Parcevaux and Sault 1984). A debond creates a channel for fluid communication and gas migration along the cement sheath. In this gap, the relative magnetic permeability decreases from the value of magnetic cement (1.5) to a value of 1 .

As shown in Fig. 7, a debond with thickness $t$ was created between the casing and cement annulus. The thickness of the annulus was $1.905 \mathrm{~cm}(0.75 ")$. Different simulations were run by varying the debond/channel thickness from $0.025 \mathrm{~cm}$ to $1 \mathrm{~cm}$. This results in a magnetic cement layer which varies from $1.88 \mathrm{~cm}$ to $0.905 \mathrm{~cm}$. As the debond thickness increased, the magnetic field strength detected at all the three sensor locations decreased in value (Fig. 8). The decrease in strength can be attributed to the reduction in thickness of the magnetic cement layer. The decrease in strength was higher at a higher value of applied current. 

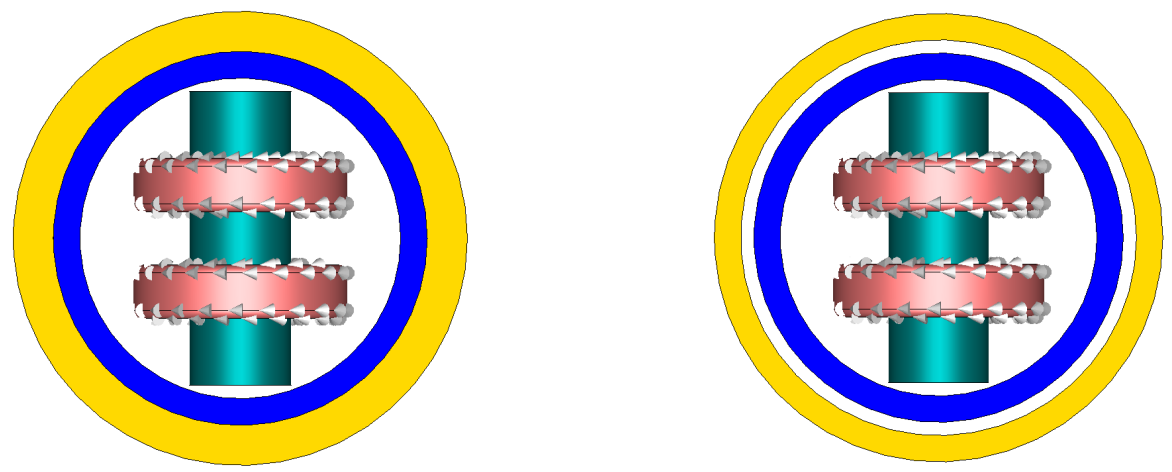

Fig. 7: Schematic of wellbore cross sections (a) with a good bond and (b) with a debond of thickness $t$, between casing (shown in blue) and cement annulus (shown in yellow).
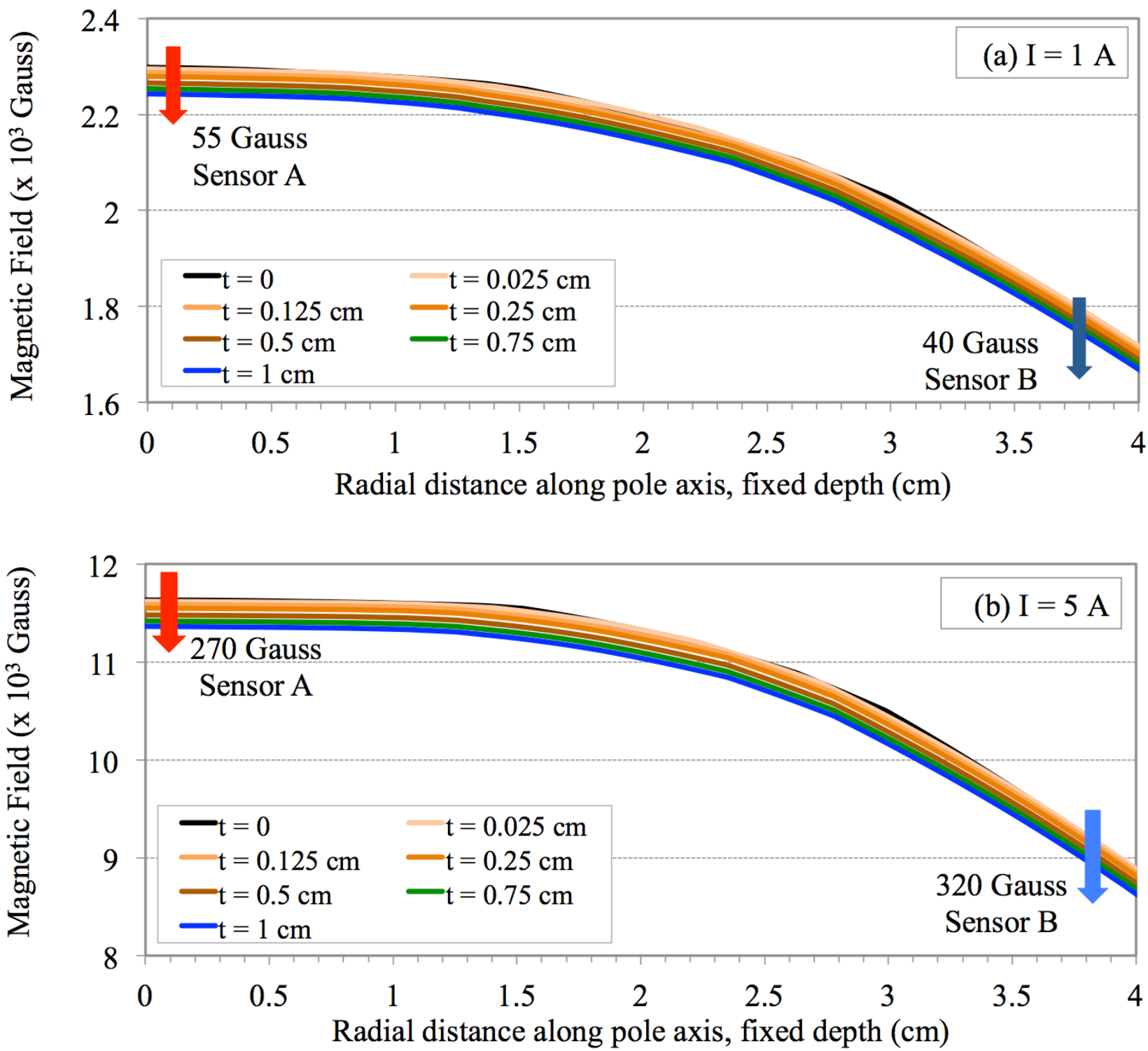

Fig. 8: Magnetic field variation inside the casing along the radial direction at $50 \mathrm{~cm}$ depth at (a) $1 \mathrm{~A}$ and (b) $5 \mathrm{~A}$ applied current. Origin is at the center of the borehole. 
Another interesting observation is that when the pole piece with coils was placed at a depth of $50 \mathrm{~cm}$, it was found that the magnetic field strength at sensors $A$ and $B$ was uniform over a depth of $3 \mathrm{~cm}$ above or below the pole piece (Fig. 9). However, the difference in field strength at location $\mathrm{C}$, which is closest to the casing was not uniform over the depth of the well.

Fig. 10 shows the influence of size of the debonding between cement annulus and casing on the magnetic field strength. At each debond size, the magnitude of the field strength was subtracted from the value when there is no debond at $50 \mathrm{~cm}$ borehole depth all three sensor locations. As the debond size increases, the difference in field strengths decreased linearly. The difference is highest at Sensor A and is lowest at Sensor C. In addition, the magnitude of the difference is significantly higher at a higher current. In practice, the magnetic sensing tool can be run over different periods of time (say months/years) and by evaluating the change in magnetic field strength, the size of the debond/channel between cement and casing can be determined.
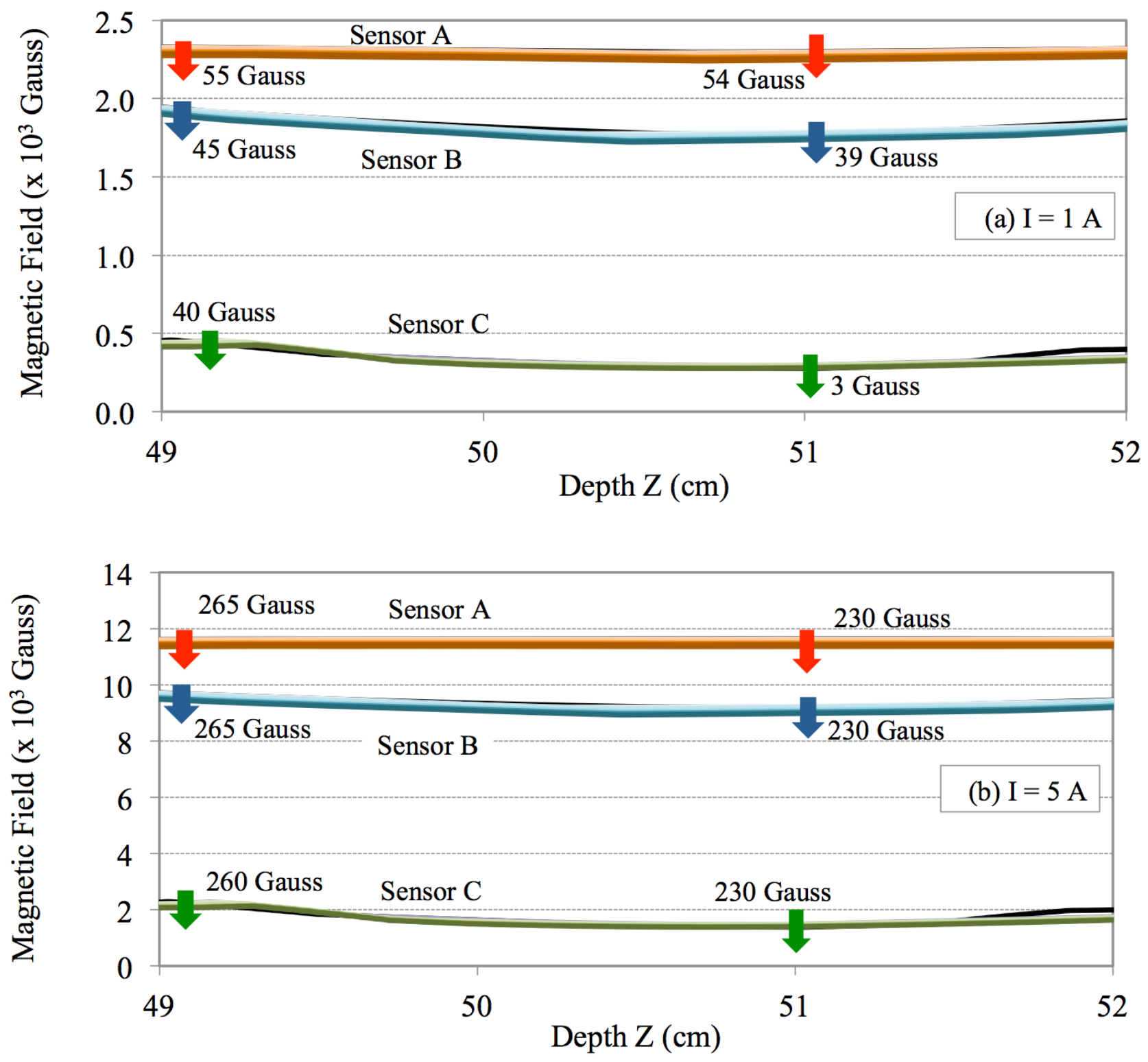

Fig. 9: Magnetic field variation along depth of well with varying debond thickness $t$ at (a) $1 \mathrm{~A}$ and (b) $5 \mathrm{~A}$ applied current. 


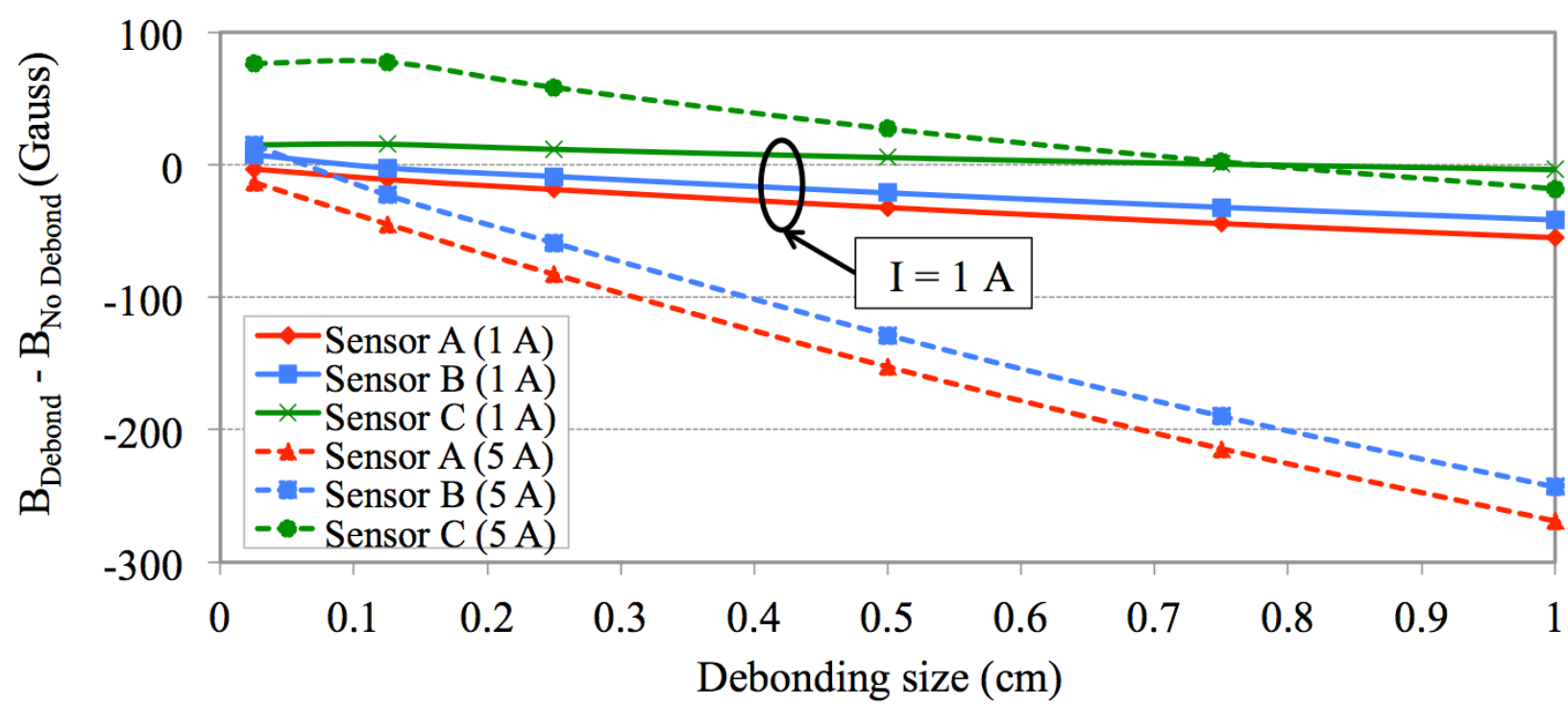

Fig. 10: Influence of magnetic field propagation depending on the presence and size of the debond between cement annulus and casing. For $1 \mathrm{~A}$ applied current, the magnitude of change in magnetic field strength with respect to no debond is smaller than in the case of $5 \mathrm{~A}$

\section{Effect of Changing Annuli Thickness}

Based on caliper logs (Elahifar et al. 2012; Market and Parker 2011; Parsons 1943) for most wells the borehole diameter is not uniform along the depth of the well. A casing with a constant thickness leads to a cement annulus with a varying thickness (ct). When the thickness of the cement annulus was increased from $0.25 \mathrm{~cm}$ to $2.5 \mathrm{~cm}$ the change in the magnetic field strength is shown in Fig. 11.

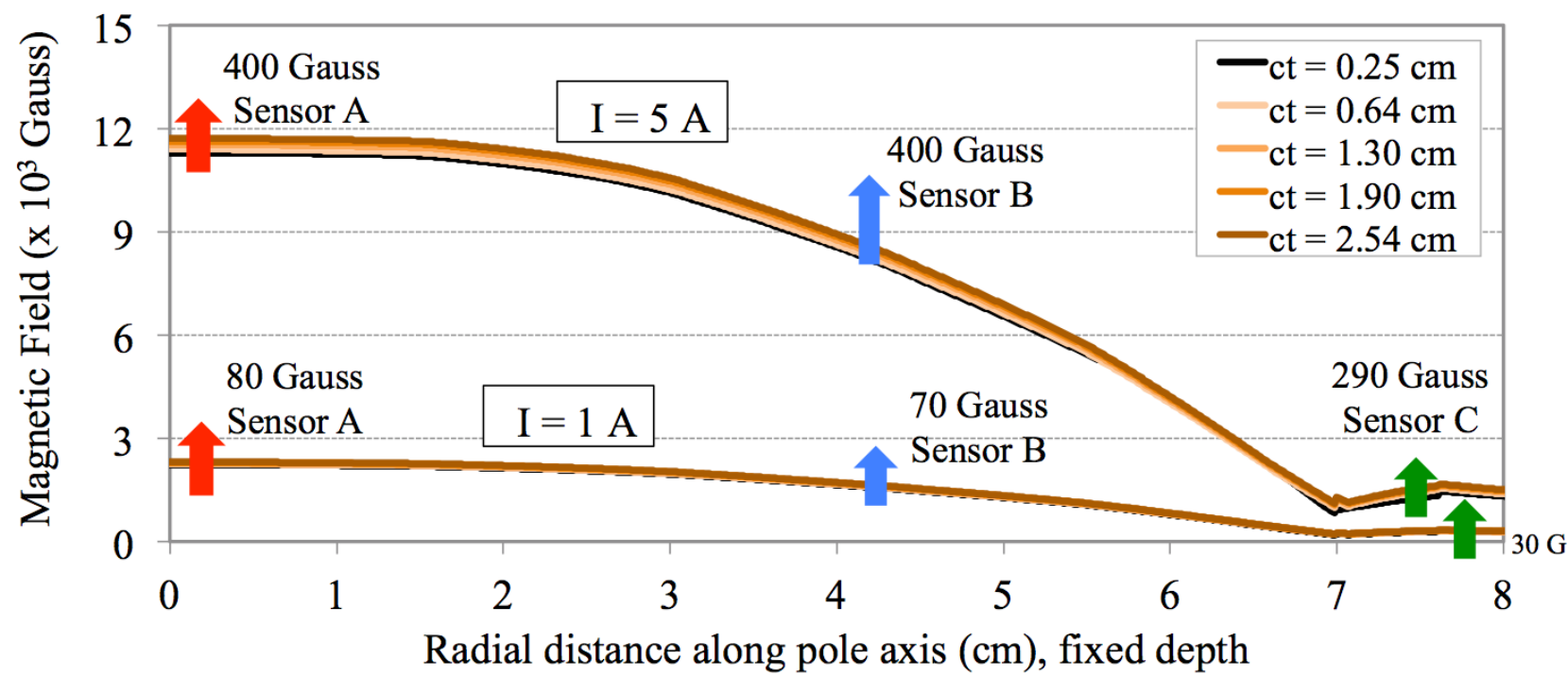

Fig. 11: Effect of changing cement annuli thickness (ct) on magnetic field. Origin is at the center of the borehole.

Previously as the debond size between cement and casing was increased, the magnetic cement layer was farther away from casing. This led to a decrease in the magnetic field strength, however in the present case a cement annuli with the same magnetic cement layer thickness has a higher strength (Fig. 12). Thus with sensitive 
magnetic sensors a debond can be differentiated from the case of changing annuli thickness. Furthermore, if debonding were to occur during the life of the well, the debond could be detected by comparing the magnetic field strength from the new log with an older log.

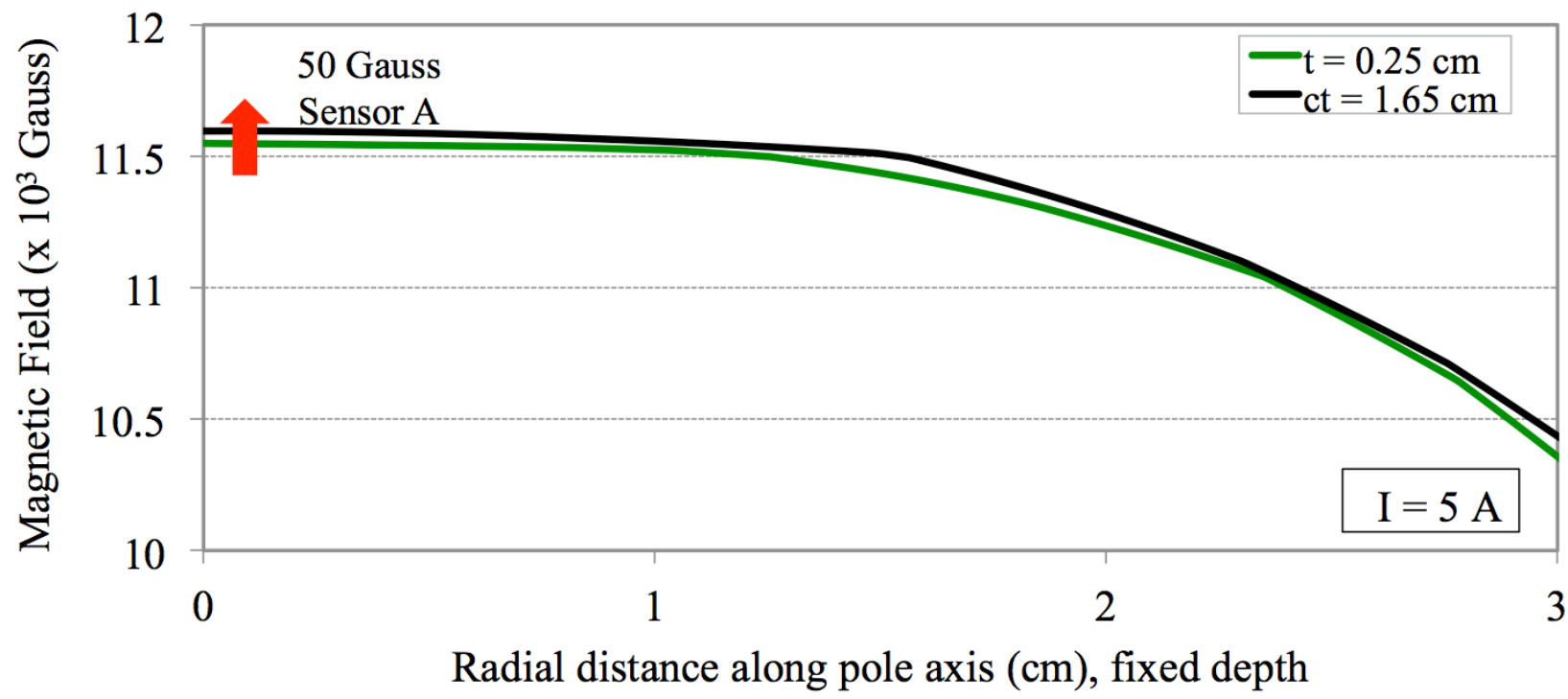

Fig. 12: Magnetic field strength for (1) a magnetic cement annulus (ct) of $1.65 \mathrm{~cm}$ and (2) annulus of $1.9 \mathrm{~cm}$ with a $0.25 \mathrm{~cm}$ debond ( $t$ ) between cement and casing resulting in a magnetic cement thickness of $1.65 \mathrm{~cm}$.

\section{Effect of Fracture in Rock Formation}

A fracture was created in the bore hole at a depth of $50 \mathrm{~cm}$ radiating from the cement annulus to approximately 30 $\mathrm{cm}$ into the rock formation (Fig. 13). Two cases were run one where the fracture was filled with magnetic cement slurry $(\mu=1.5)$ and another when the fracture was filled with drilling fluid (DF, $\mu=1$ ). As shown in Fig. 14, at 5 A applied current, the magnetic field strength in the fracture filled with magnetic cement is higher in strength by 140 Gauss compared to the case when the fracture is filled with drilling fluid. However, the magnetic field strength inside the casing and the cement annulus is not affected by the presence of the fracture (Fig. 15). Furthermore, the pole piece with coils was rotated by $90^{\circ}$ to determine if the asymmetrical fracture can be detected, but as shown in Fig. 15, the magnetic field strength along the axis of the pole piece was similar for both the cases. It can be concluded that the thick magnetic cement layer has a significant influence over the propagation of magnetic field lines and thus the field is not affected by the presence of a fracture in the rock formation.

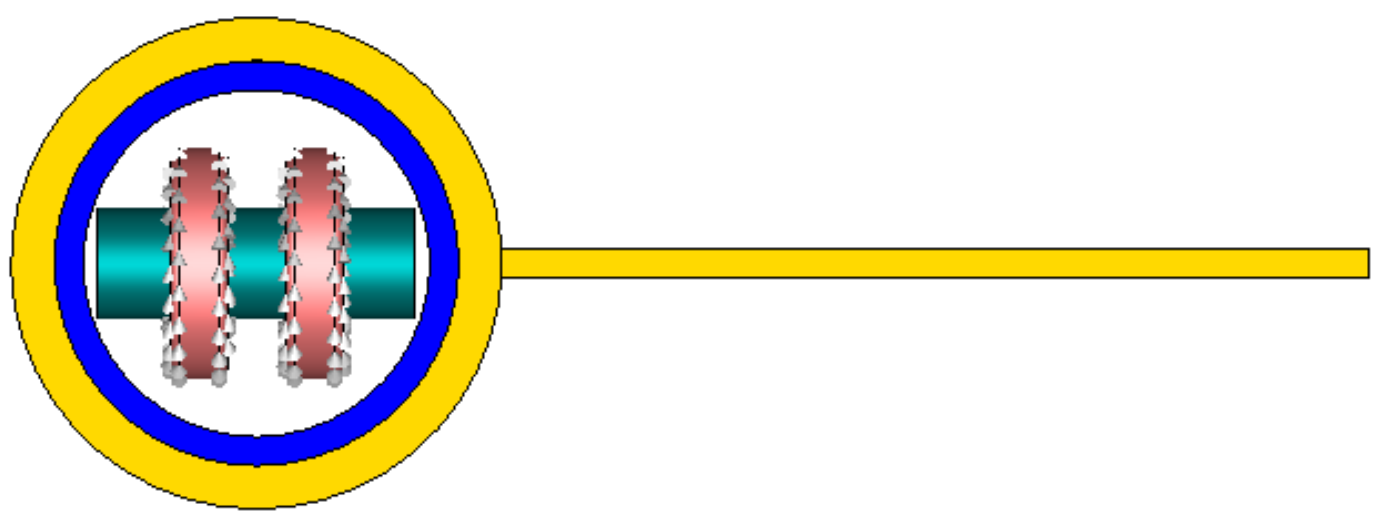

Fig. 13: Presence of a fracture filled with magnetic cement in the rock formation. 


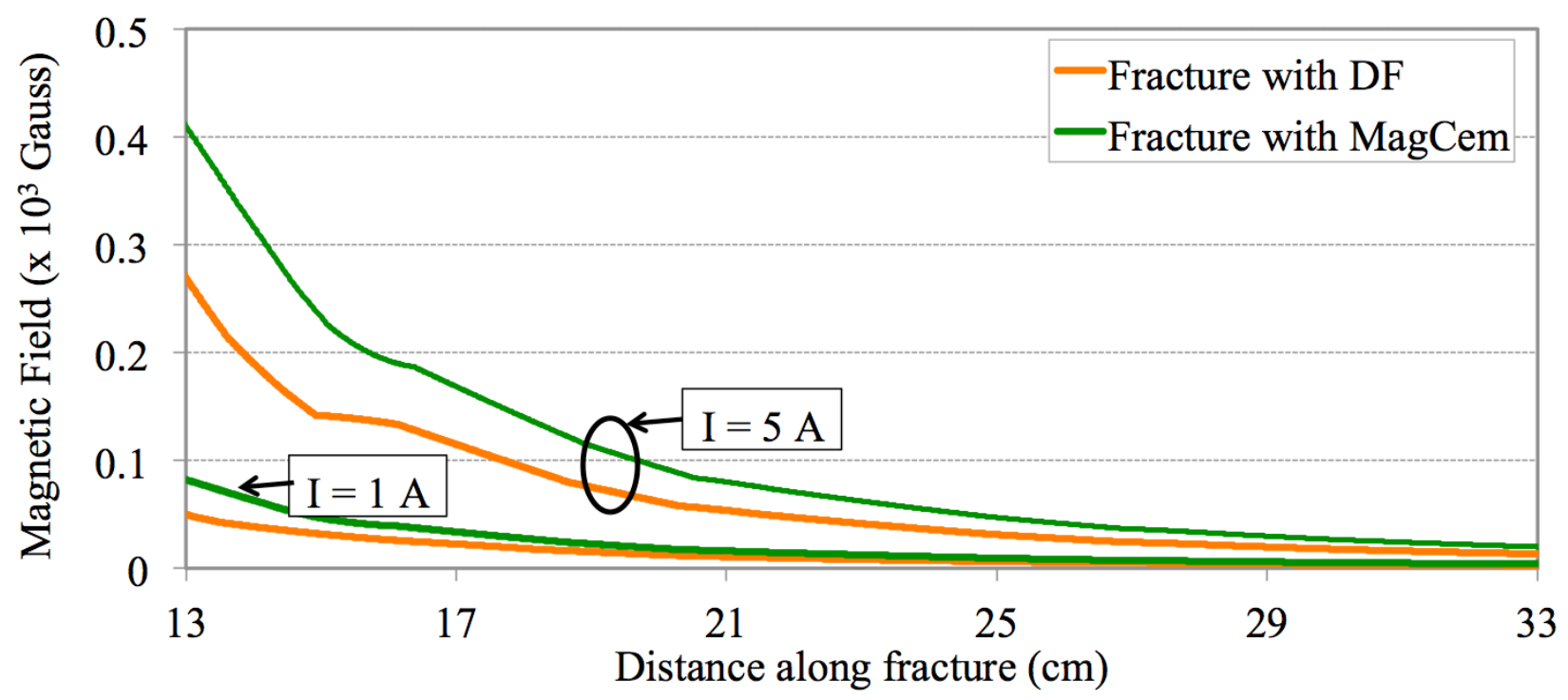

Fig. 14: Magnetic field strength in the fracture filled with magnetic cement is higher than the case when it is filled with drilling fluid.

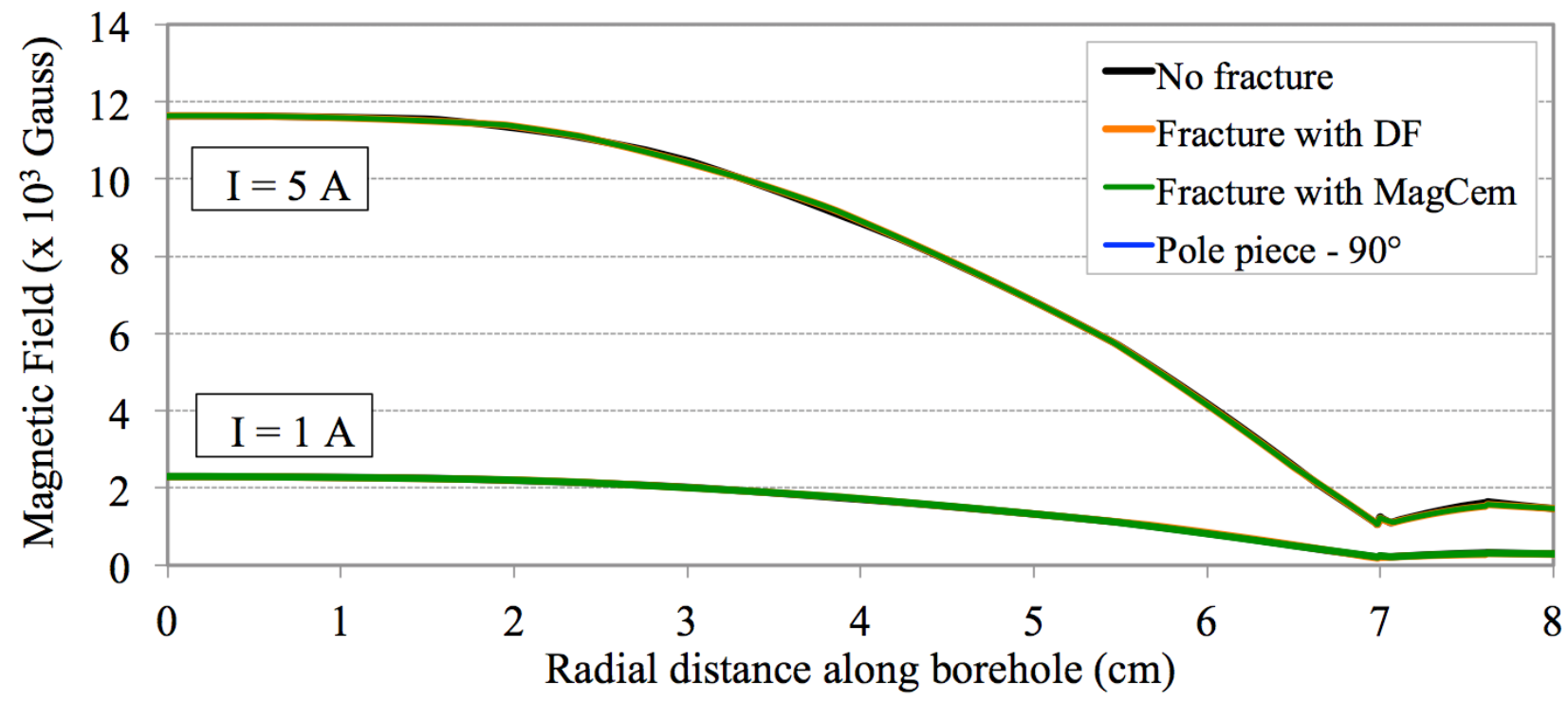

Fig. 15: Effect of fracture on the magnetic field strength inside the cased hole.

\section{Effect of varying magnetic permeability of cement slurry}

With an increase in the complexity of the wells being drilled, cement displacement is an ever growing challenge. Even with the use of fluids with appropriately designed viscosities and gel strengths, insufficient stand-off / centralization of the casing or liner, absence of casing / liner rotation during cementing, poor borehole condition (i.e. presence of borehole rugosity), are all factors that increase the likelihood that cement slurry can be contaminated with drilling fluid or in some cases lead to formation of mud channels that could potentially change the magnetic permeability of the slurry behind the casing. When the magnetic permeability of the cement annulus was increased form 1.0 to 1.5, the magnetic field strength increased by 70-80 Gauss at $1 \mathrm{~A}$ and by 420 Gauss at $5 \mathrm{~A}$ current (Fig. 16). This change is uniform over the depth of the well at both sensors A and B (Fig. 17). From the caliper log, significant deviation in magnetic field strength from the expected values can be attributed to potential contamination or inefficient displacement of the cement slurry. 


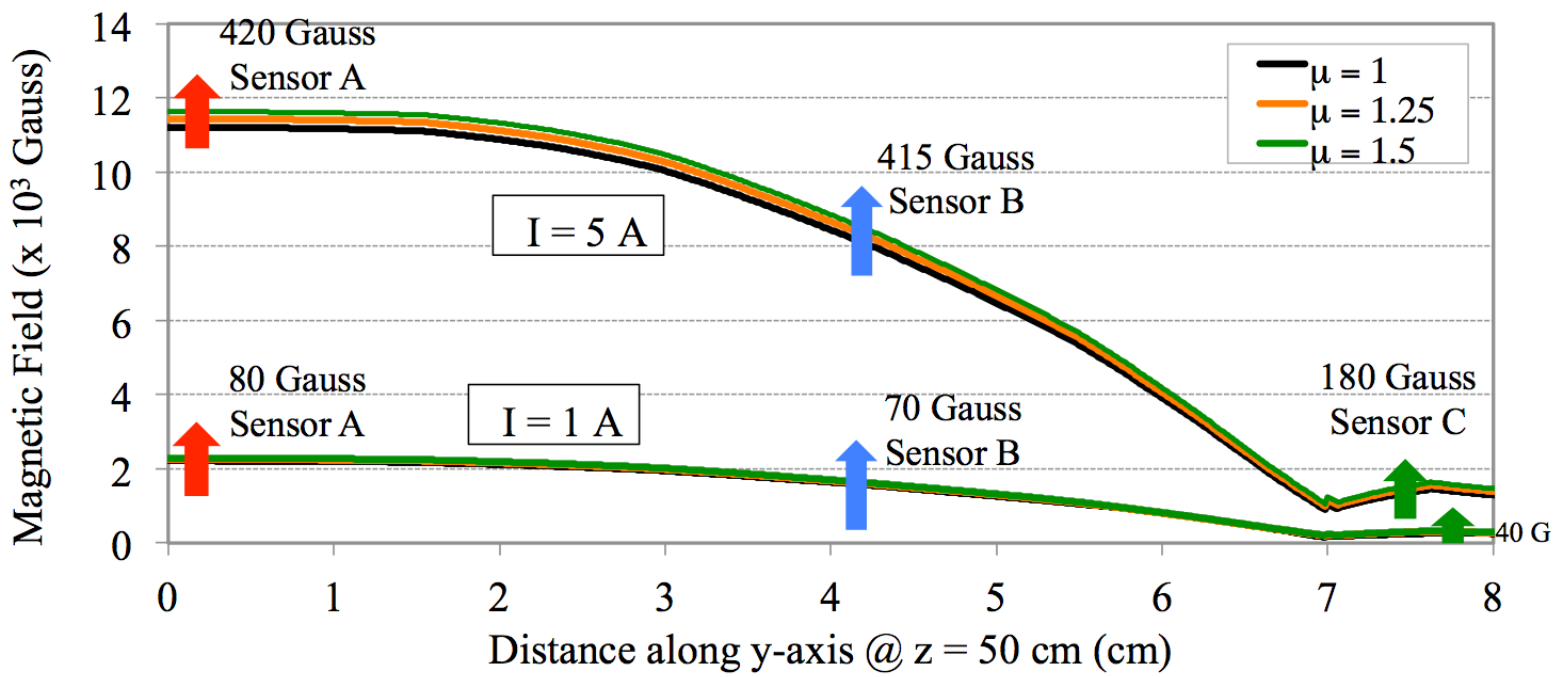

Fig. 16: Effect of varying magnetic permeability on the magnetic field strength.
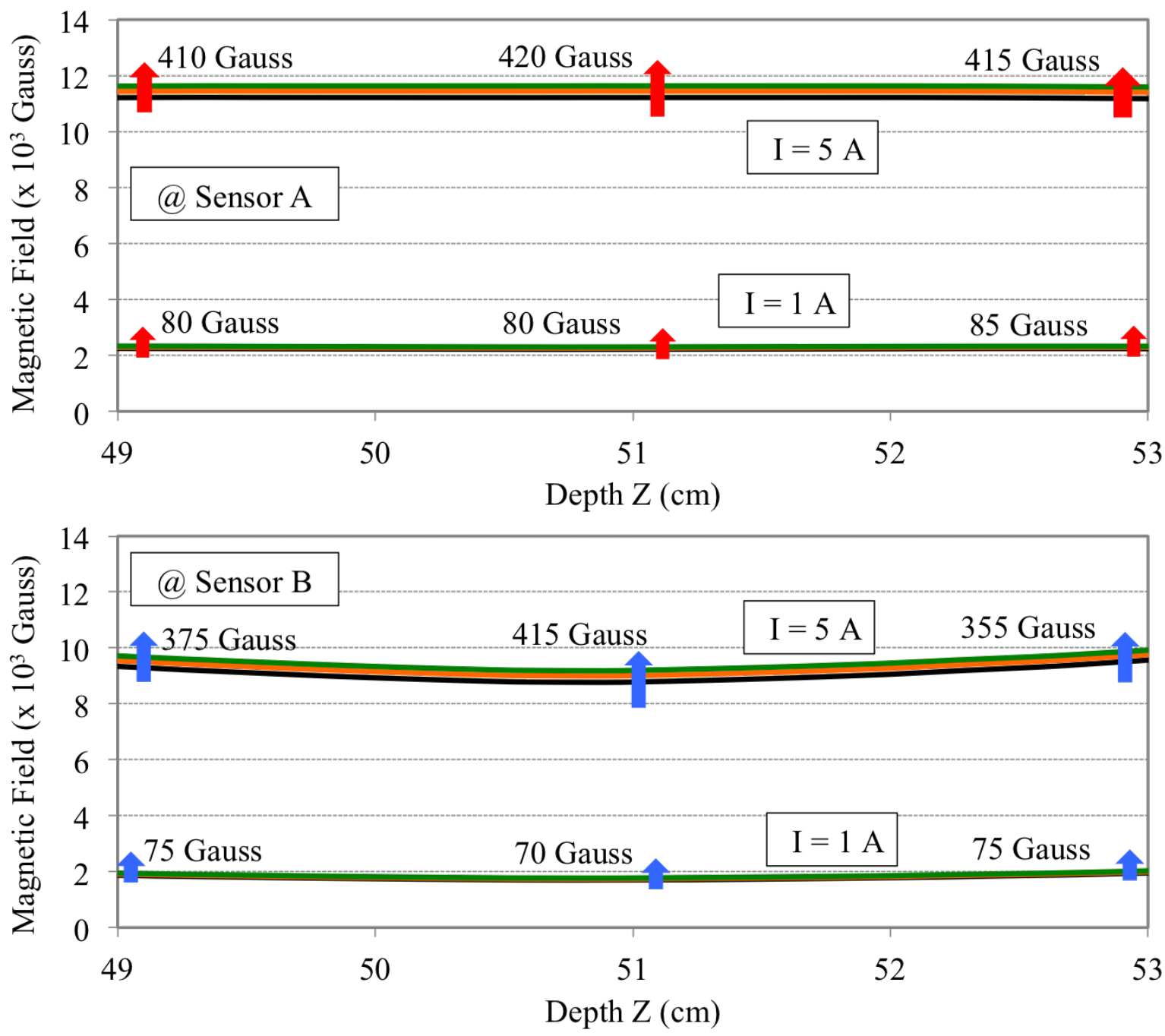

Fig. 17: Magnetic field variation along depth of well at sensor locations A and B. 


\section{Influence of Annuli Eccentricity}

It is possible for the casing to be not uniformly centered in the borehole leading to a cement annulus with an eccentricity. This commonly happens in the case of directional/horizontal drilling when casing centralization and the creation of sufficient stand-off is insufficient and/or when borehole caliper is poor (Nelson and Guillot 2006). In this situation, cement preferably flows through the wider annular gap and drilling fluid is left behind in the narrower gap (Fig. 18 b-d), thus creating a mud channel. A mud channel that runs along the length of the well can lead to migration of unwanted fluids, which can contaminate water aquifers and increase the risk of well control incidents. Thus it is essential to find such channels.

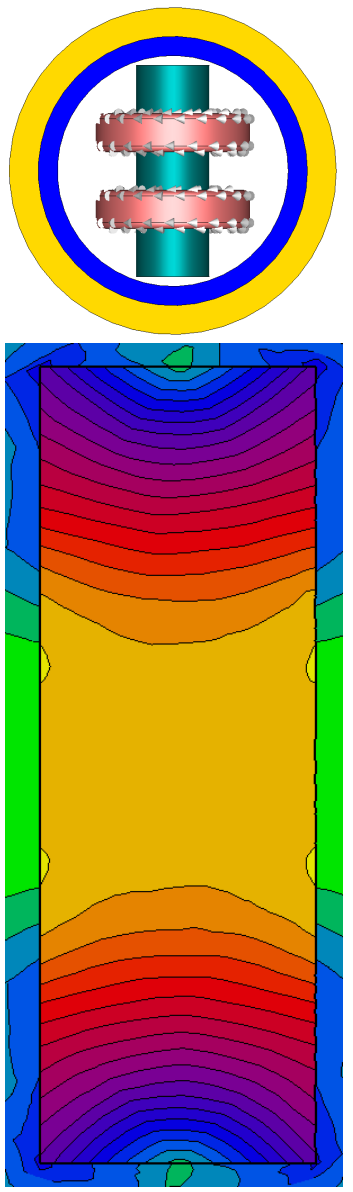

(a) Concentric
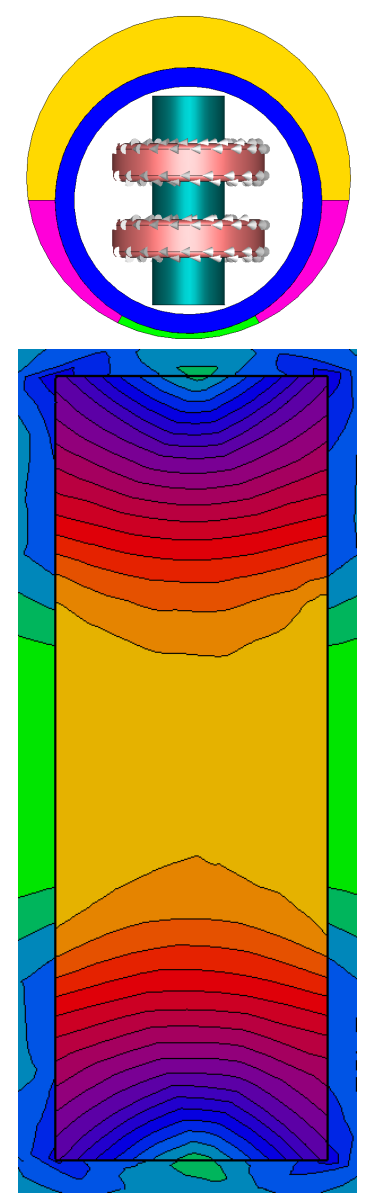

(b) $\alpha=0$
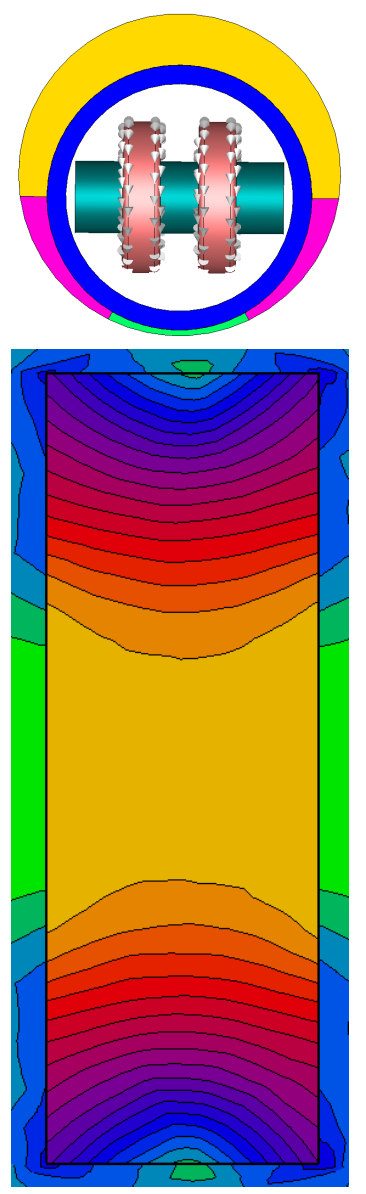

(c) $\alpha=90$
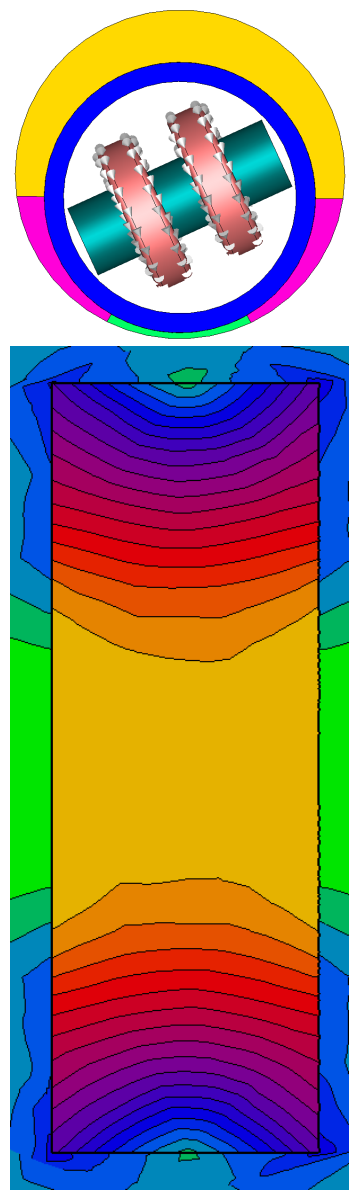

(d) $\alpha=60$

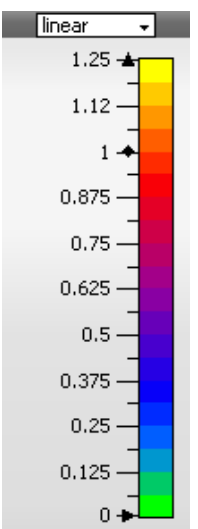

(e) Tesla

Fig. 18: Magnetic field strength (Tesla, 10000 Gauss) contours near pole piece for (a) concentric annuli uniformly filled with magnetic cement slurry (b-d) eccentric annuli filled non uniformly with magnetic cement slurry (shown in yellow) in the widest part of annulus, drilling fluid (shown in green) in the narrowest part of the annulus and a contaminated slurry mixed with cement and drilling fluid (shown in magenta). The pole piece was rotated at different angles, $\alpha$. Applied current was 5 A.

The pole piece with coils was used to apply magnetic field in the eccentric borehole. As shown in Fig. 18, the pole piece with coils was rotated in the annulus in an attempt to detect mud channels. However, as the pole piece spans the entire diameter of the cased hole, when one end of the pole piece faces the wider part, the other end faces the narrower part. Thus, the magnetic field strength was similar in all the cases shown. To overcome this affect, the pole piece was shortened such that it spanned from the center of the borehole to the edge of the casing (Fig. 19). 


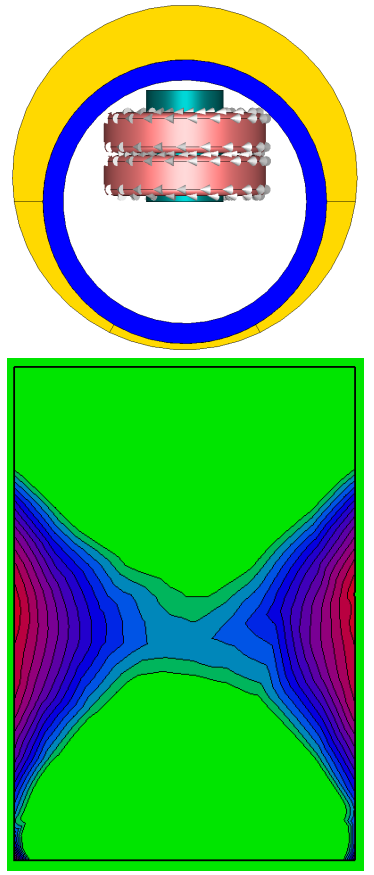

(a) $\alpha=0$ $\mu=1.5$
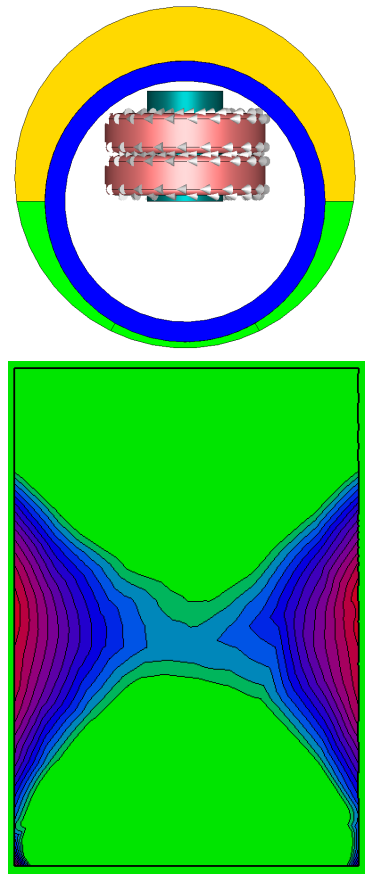

(b) $\alpha=0$ $\mu=1 \sim 1.5$
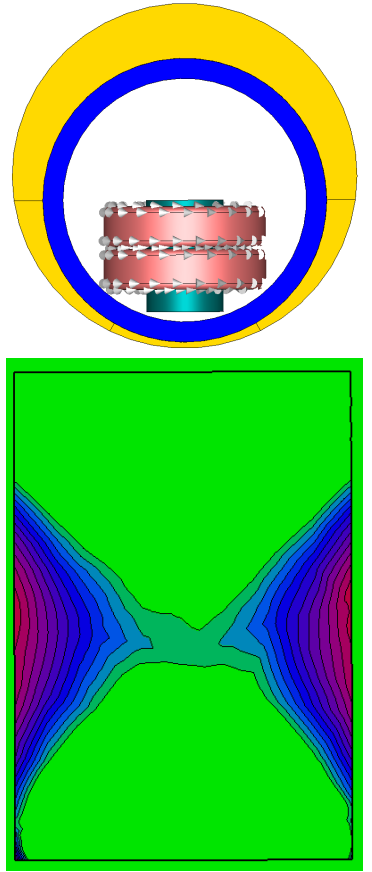

(c) $\alpha=180$

$\mu=1.5$
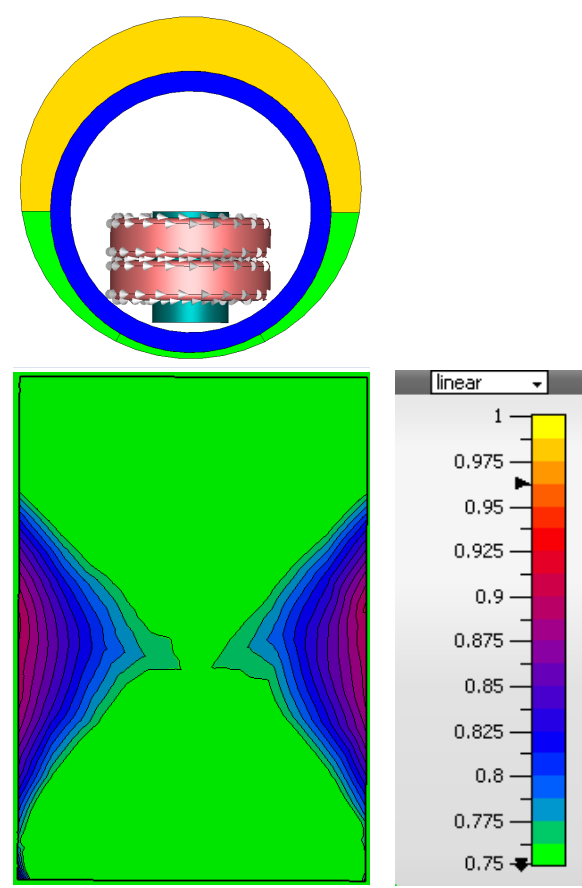

(d) $\alpha=180$

$\mu=1 \sim 1.5$ (e) Tesla $10000 \mathrm{G}$

Fig. 19: Eccentric annuli $(a, c)$ filled uniformly with magnetic cement and $(b, d)$ filled non uniformly with magnetic cement and drilling fluid (current $=5 \mathrm{~A}$ ).

With the shorter pole piece as shown in Fig. 19, two cases were considered; (1) when the eccentric annuli is uniformly filled with magnetic cement $(\mu=1.5)$ and (2) when the eccentric annuli was filled with magnetic cement on the wider part $(\alpha=0)$ and drilling fluid $(\mu=1)$ on the narrower part $(\alpha=180)$. In both cases when the pole piece was placed closer to the widest part, the magnetic field lines were similar (Fig. 20). When the pole piece was placed closer to the narrower part, there was a difference in magnetic field strength based on the fluid in that region (Fig. 20). Thus by using a shorter pole piece mud channels can be detected using sensitive magnetic sensors.

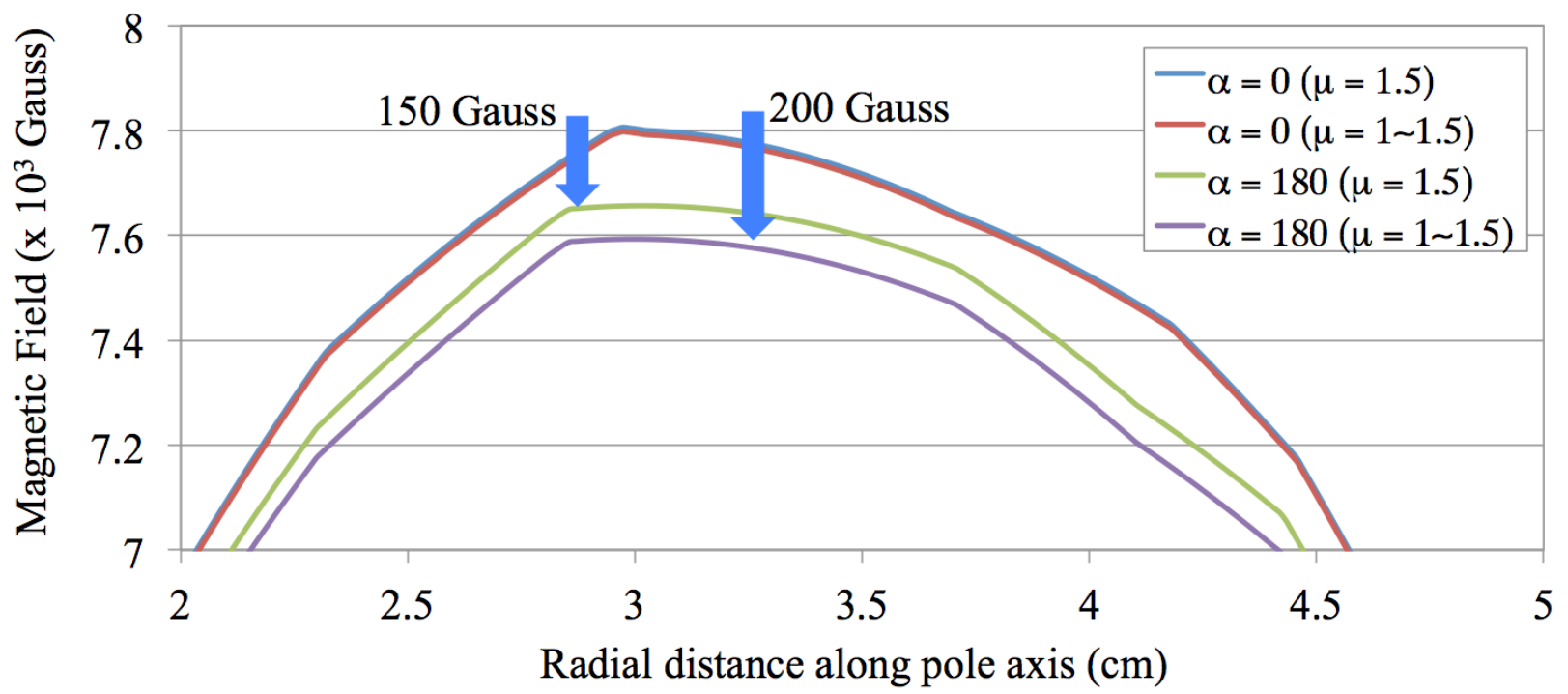

Fig. 20: Effect of fluid composition on magnetic field strength in an eccentric annulus at $5 \mathrm{~A}$ current. 
Next, the shorter pole piece was used in an eccentric annulus filled with magnetic cement slurry in the wider part, drilling fluid in the narrower part with a contaminated fluid $(\mu=1.25)$ inbetween the two (Fig. 21). As the pole piece was rotated at different angles, there was a detectable variation in the magnetic field strength at various locations (Fig. 22). Thus, by comparing the magnetic field strength with respect to a reference angle, the state of the cement annulus can be determined.
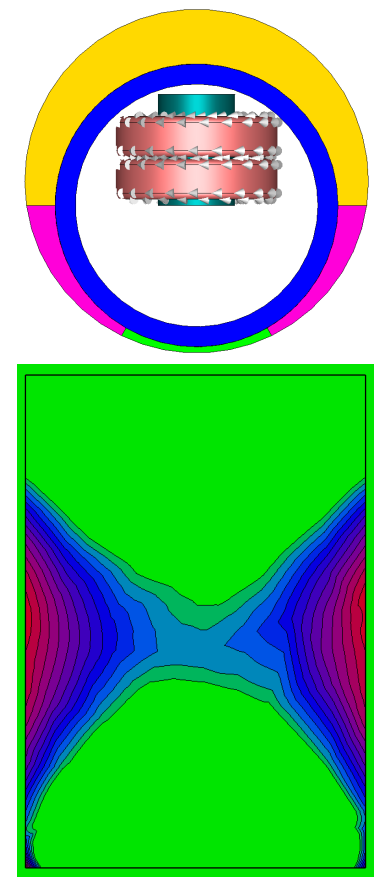

(a) $\alpha=0$
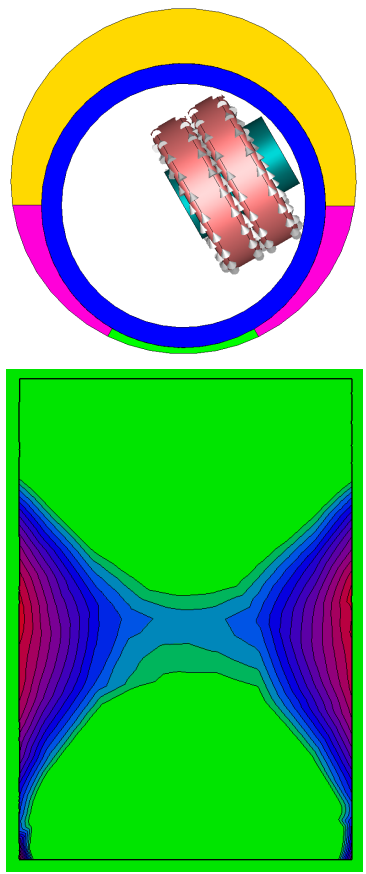

(b) $\alpha=60$
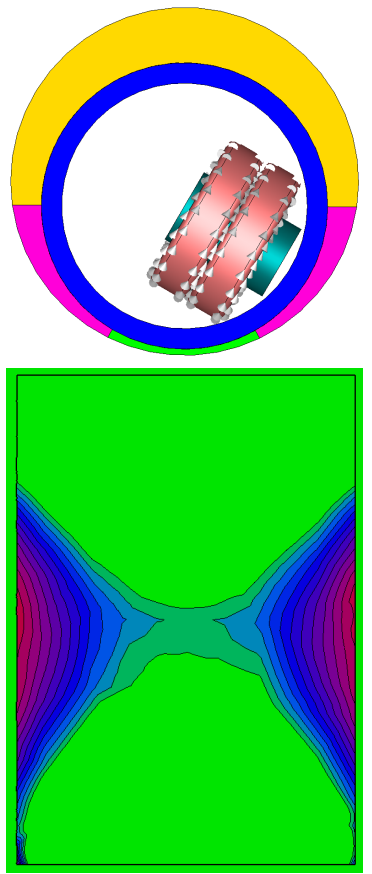

(c) $\alpha=120$
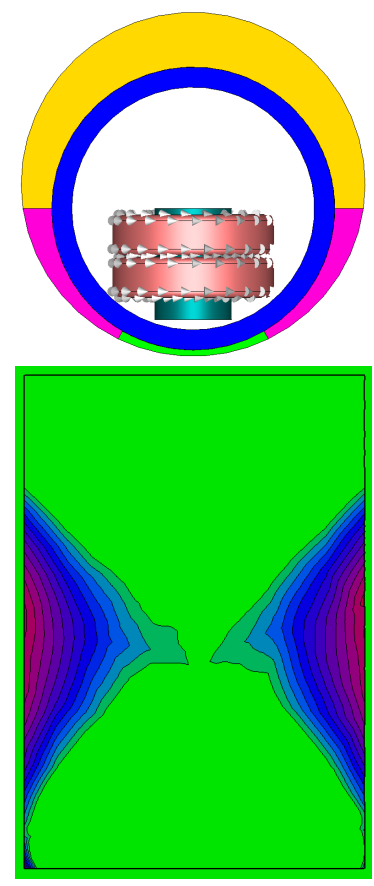

(d) $\alpha=180$

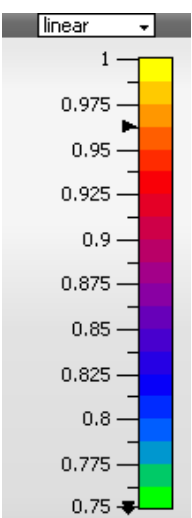

(e) Tesla

Fig. 21: Effect of non uniformly displaced eccentric cement annulus on magnetic field contours at 5 A current.

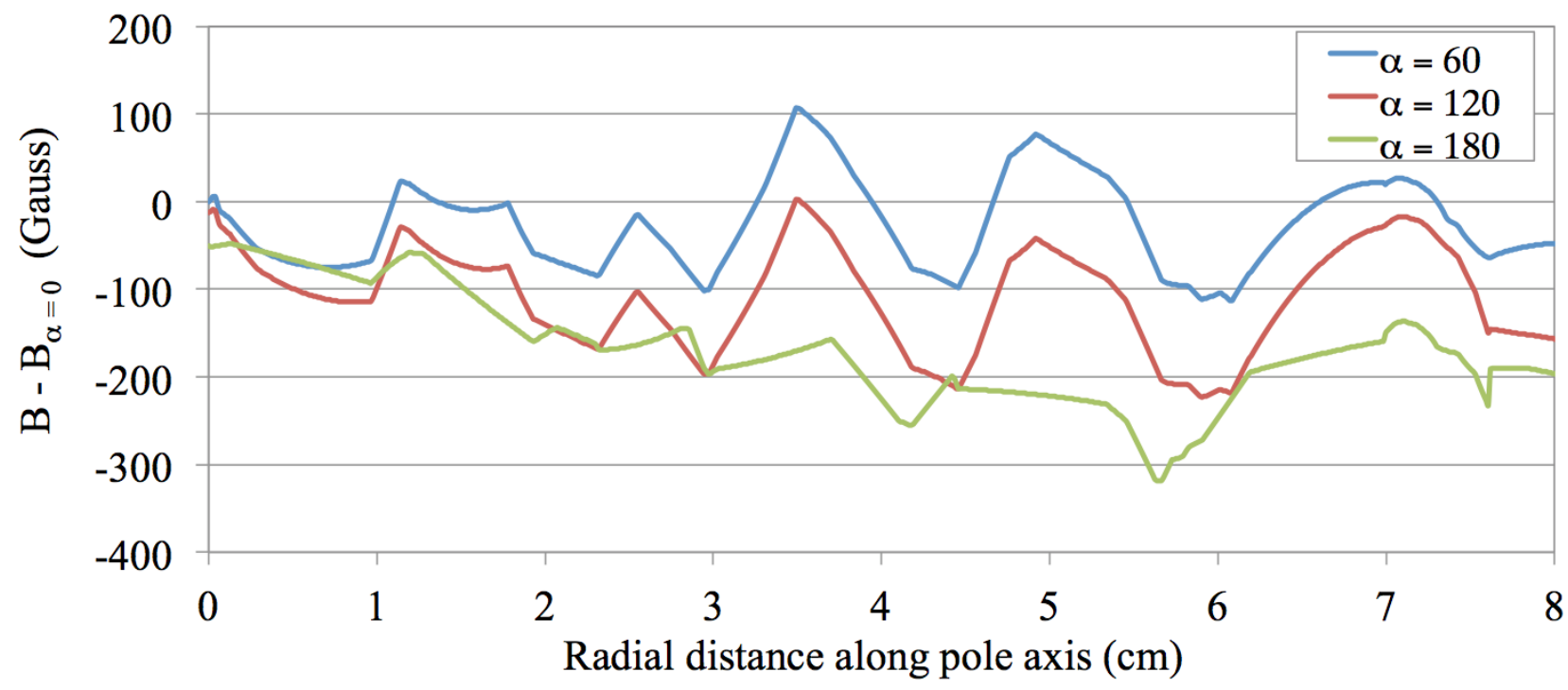

Fig. 22: Difference in magnetic field strength with respect to a reference angle at $5 \mathrm{~A}$ current with a shorter pole piece. 


\section{Conclusions}

Based on the 3D numerical simulations, the proposed approach appears to be viable for evaluating the quality of the cement annulus to ensure good zonal isolation. It was found that when a current was passed through the electric coils, magnetic field lines passed through the stainless steel casing, the cement annulus and the rock formation. The magnetic field strength in the annulus was affected by the magnitude of current that is passed through the coil as well as by well geometry. The path as well as the strength of the magnetic field lines change based on the thickness of the magnetic layer. This implies that varying annuli thicknesses due to borehole irregularity can be detected. Presence of a debond or a channel between cement annulus and casing can also be detected by comparing the magnetic field strength to a previously obtained log. Furthermore, in eccentric annuli, uncemented sections on the narrow side could be differentiated from well cemented narrow sections, which facilitates the detection of mud channels. Contamination of magnetic cement slurry with drilling fluid would reduce the magnetic permeability of cement slurry, which can be detected by monitoring the magnetic field strength in the cased borehole. Thus, the proposed magnetic approach appears to be viable for evaluating the quality of the cement annulus to ensure good zonal isolation.

\section{References}

Carpenter, R. B., J. L. Brady, and C. G. Blount, The effects of temperature and cement admixes on bond strength, Journal of Petroleum Technology, 44(8), 880-885, doi:http://dx.doi.org/10.2118/22063-PA, 1992.

Dennison, E., Magnetic formulas http://nbviewer.jupyter.org/github/tiggerntatie/emagnet-py/, 2015.

Deshmukh, S., Development, characterization and applications of magnetorheological fluid based 'smart' materials on the macro-to-micro scale, Ph.D. thesis, MIT, 2007.

Elahifar, B., A. Esmaeili, R. K. Fruhwirth, and G. Thonhauser, Real time measurement of borehole shape and diameter by using ultrasonic caliper in different drilling fluid and wellbore conditions for detecting instabilities, SPE Canadian Unconventional Resources Conference, 162251-MS, doi:http://dx.doi.org/10.2118/162251-MS, 2012.

Ermila, M., A. Eustes, and M. Mokhtari, Using magneto-rheological fluids to improve mud displacement efficiency in eccentric annuli, SPE, 160966-MS, doi:https://doi.org/10.2118/160966-MS, 2012.

Ermila, M., A. W. Eustes, and M. Mokhtari, Improving cement placement in horizontal wells of unconventional reservoirs using magneto-rheological fluids, Unconventional Resources Technology Conference, 1619212-MS, 2013.

Izon, D., E. Danenberger, and M. Mayes, Absence of fatalities in blowouts encouraging in MMS study of OCS incidents 1992-2006, Drilling Contractor, pp. 84-90, 2004.

Lai, J. K. L., C. H. Shek, and K. H. Lo, Stainless Steel An Introduction and Their Recent Developments., Bentham Science Publishers, 2012.

Market, J., and T. J. Parker, Reliable Iwd calliper measurements, SPE Offshore Europe, 146245-MS, doi:http://dx.doi.org/10.2118/146245-MS, 2011.

Nair, S. D., Adaptive performance of cement-based materials using a magnetorheological approach, Ph.D. thesis, The University of Texas at Austin, Austin, TX, 2013.

Nair, S. D., Q. Wu, M. Cowan, and E. van Oort, Cement displacement and pressure control using magneto-rheological fluids, SPE/IADC, 173124-MS, doi:http://dx.doi.org/10.2118/173124-MS, 2015. 
Nelson, E. B., and D. Guillot, Well cementing, second ed., Schlumberger, Texas, USA, 2006.

Parcevaux, P. A., and P. H. Sault, Cement shrinkage and elasticity: A new approach for a good zonal isolation, SPE/ATCE, (13176-MS), doi:http://dx.doi.org/10.2118/13176-MS, 1984.

Parsons, C. P., Caliper logging, SPE:Transactions of the AIME, 943035-G, doi:http://dx.doi.org/10.2118/943035-G, 1943.

Sabins, F., Ultra-lightweight cement slurries improve cement performance, GasTIPS, 8(4), 4-7, 2002.

West, L., How do oil spills damage the environment? http://environment.about.com, 2011. 